\title{
Performance Measurement of a Compact Generator - Hydro Turbine System
}

\author{
Pudji Irasari*, Priyono Sutikno**, Puji Widiyanto***, Qidun Maulana* \\ * Research Centre for Electrical Power and Mechatronic, Indonesian Institute of Sciences, Indonesia \\ ** Fluid Machinery Laboratory, Faculty of Mechanical and Aerospace Engineering, Institut Teknologi Bandung (ITB),
} Indonesia

\section{Article Info}

Article history:

Received Jun 3, 2015

Revised Jul 29, 2015

Accepted Aug 15, 2015

\section{Keyword:}

Low speed

Permanent magnet generator

low head

Stator inner casing material

Water turbine

\begin{abstract}
This study aims to investigate the characteristic of a compact generator hydro turbine system. The generator is of permanent magnet type and the turbine operates in a very low head. The integration of the two components is conducted in such a way that simplifies the construction of the conventional turbine generator. The method is by mounting the generator stator to the turbine casing and the permanent magnets are assembled in the perimeter of the turbine blade rotor. This simple construction is approached by making the stator from individual teeth and yoke. The permanent magnet generator (PMG) is designed to produce the nominal power of 300 Watt $50 \mathrm{~Hz}$ at 83 rpm of turbine shaft. All components of the integrated turbine- generator are totally immersed in the water stream. The stator has to be hermitic to avoid water entering the spool. Another issue investigated is the influence of the type of the stator inner casing material to the generator performance. The results show, the PVC material for inner casing has a good influence to the generator performance compared with the mild steel material.
\end{abstract}

Copyright (C) 2015 Institute of Advanced Engineering and Science. All rights reserved.

\section{Corresponding Author:}

Pudji Irasari

Research Centre for Electrical Power and Mechatronic, Indonesian Institute of Sciences,

Komplek LIPI, Jl. Sangkuriang Gd. 20, Lt. 2, Bandung 40135

West Java-Indonesia

Email: pirasari@yahoo.com/pudj002@lipi.go.id

\section{INTRODUCTION}

In the last decade, the exploration of the very low head hydro power (VLHHP) becomes more attractive in line with the improvement of the technology of low speed generator and very low head water turbine. VLHHP installed at low potential energy sources or low head, like irrigation conduit, usually operates in the run of the rivers which are mostly easily accessible locations and near load center. Therefore, it saves the cost of transmission and facilitates the operation and maintenance. In addition, the VLHHP is also considered environmentally friendly.

Usually VLHHP system is simply immersed in river stream with a relatively low head (below 2 meters), available in irrigation system with a small dam. To increase the added value of a water gate, occasionally VLHHP system is integrated in it. The elevation of low head is usually defined as less than $40 \mathrm{~m}$ [1] and very low head has a potential head of less than 2 meters. Most of VLHHPs are made in a small capacity, usually in pico scale $(\leq 5 \mathrm{~kW})$. Nowadays, the capacity has reached up to hundreds of watts per unit [2] and will continue to increase. Under the capacity of $5 \mathrm{~kW}$, pico hydro power is considered as a cost effective and reliable power supply for off-grid stand-alone generators, and has also been shown to be one of the most cost-effective off-grid energy solutions [3]. Nevertheless, for power of above $5 \mathrm{~kW}$, there are still a lot of efforts should be done to achieve its economic viability. 
Many studies related to VLHHP technology have been conducted, either as individual component or as a whole system. Research and development of low head hydro turbines can be found in [4]-[7], and the studies on overall system with the goal of getting a more economic system or a better performance system were performed by [8], [9]. Another main component, low speed generator, has been popular first for wind energy applications followed by ocean and low head hydro energy. The most used generator for low speed applications are of permanent magnet type. The other types, i.e. induction or asynchronous generator and synchronous generator are usually designed in high speed. However, since induction generator is relatively cheap and easy to find in the market, the utilization of this type of generator, for wind, hydro or ocean energy, is still high although a mechanical transmission is needed. The applications of induction generators for wind turbine are studied by [10], [11], whilst investigation on low speed PMG and its application are discussed in [12]-[15].

Considering that the system should be compact, this research is aimed to build a low speed permanent magnet generator (PMG) that can be simply integrated with a low head hydro turbine. For that purpose, an integrated stator with individual teeth and yoke is considered to be the simplest and the most appropriate construction. Another studied issue is the influence of the type of the stator inner casing material to the generator performance. This is substantial as the VLHHP system will be operated totally immersed in water so there will be water gap instead of air gap. The design and performance of the generator are validated using laboratory experiment.

\section{RESEARCH METHOD}

\subsection{Design Strategy}

The turbine is designed to generate power of $300 \mathrm{~W}$ at $83 \mathrm{rpm}$. The requirement is that the perimeter of the turbine blades possessing the diameter of $600 \mathrm{~mm}$, serves as the rotor generator at once (Figure 1). In compliance with that, the integrated stator with individual teeth and yoke would be the selected solution. The material of the iron yoke is mild steel (St37) and the teeth utilize I part of the transformer lamination.

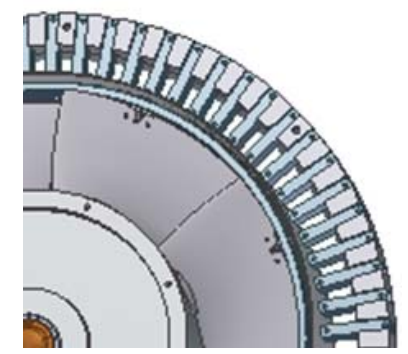

Figure 1. Turbine-generator construction

Generally, standard electric machines apply stator material that is entirely made of silicon steel sheet lamination. Both sides of the lamination are isolated to minimize core loss, particularly Eddy current loss that generates heat in the machine. Nevertheless, the use of silicon steel sheet requires a high cost dies to cut the lamination into desired pieces. Therefore, stator with different materials for yoke and teeth is regarded more appropriate for this study. The yoke can be shaped by machining process and the teeth are arranged from transformer laminations which are available in the market in various dimensions. The heat caused by core loss is assumed not to affect the performance of the generator since the system is thoroughly submersed into the water during the operation. Detailed procedure in designing every main component is described in the following sections.

\subsection{Stator Design and Construction}

Stator has slots in which the windings are installed.The accuracy in determining stator dimension will affect the performance of the generator. The bigger the dimension of the yoke and the teeth, the more expensive the machine will be. On the other hand, if the dimension is too small, the flux density will increase that may lead to overheating or higher harmonic content. A common equation applied to predict the output power is:

$$
P=D^{2} \cdot L_{i}
$$


where $P$ is the power output (W), $D$ is the inner stator diameter, and $L_{\mathrm{i}}$ is the effective length of the stator core. In this case, the rotor diameter is already known and the radial length of the water gap is set at $5 \mathrm{~mm}$ considering the mechanical construction. Regarding that, looking back to equation (1), the only variable that enables to be adjusted is the length of the core laminations. Number of stator poles can be calculated using Equation (2),

$$
n_{s}=\frac{120 \cdot f}{2 p}
$$

Substituting the turbine's rotation $n_{\mathrm{s}}$ of $83 \mathrm{rpm}$ and the nominal frequency $f$ of $50 \mathrm{~Hz}$, the number of poles $2 p$ is obtained as 72 . Generator is designed with single phase winding and the number of slots per pole per phase $q$, equals to 1 .

Furthermore, the poles are distributed evenly with the help of CAD design software. This stage is conducted with little trial and error by applying one at a time some possible dimensions of the transformer lamination. To meet the desired design, the selected dimension of the stator teeth is $0.013 \mathrm{~m} \times 0.07635 \mathrm{~m}$. The stator depth is obtained after determining the ratio of stator width to stator depth as 0.4 .

Concerning the stator inner casing materials, polyvinyl chloride (PVC), and mild steel (St37) are the two selected materials to be investigated, with the position as shown in Figure 2.

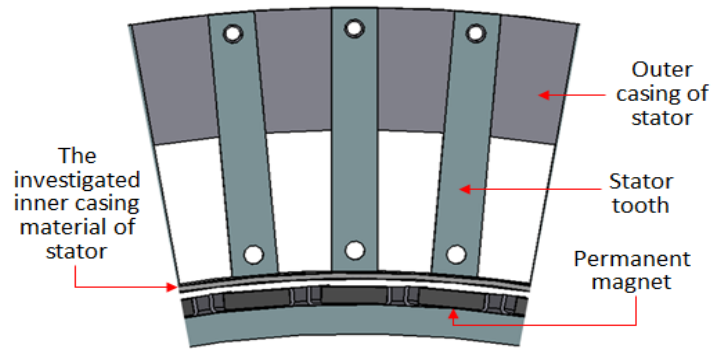

Figure 2. The position of the investigated stator casing material

The thickness of the stator inner casing is $2 \mathrm{~mm}$. St37 is one of low carbon steels or mild steels categorized in normal strength and extensively used in diverse industries especially for the fabrication of automobile chassis and bodies [16], [17]. As for PVC, it is one of the most widely used of all plastics, having tough, strong, good low temperature characteristics, as well as flame-retardant properties. However, it does not retain good mechanical performance above $80^{\circ} \mathrm{C}$ [18].

\subsection{Winding Number and Parameters}

Considering its dimension, the power produced by the generator is relatively small, which is only $300 \mathrm{~W}$. Winding number is presented by,

$$
\begin{aligned}
& N_{p h}=\frac{E_{p h}}{4.44 \cdot f \cdot \phi \cdot k_{w}} \\
& \phi=B_{g} \cdot A_{m} \\
& k_{w}=k_{d} \cdot k_{p} \cdot k_{s}
\end{aligned}
$$

With $E_{\mathrm{ph}}$ is the back electromotive force $(\mathrm{V}), f$ is the frequency $(\mathrm{Hz}), \phi$ is the magnetic flux $(\mathrm{Wb}), k_{\mathrm{w}}$ is the winding factor, $B_{\mathrm{g}}$ is the stator teeth flux density $(\mathrm{T}), A_{\mathrm{m}}$ is the permanent magnet area $\left(\mathrm{m}^{2}\right), k_{\mathrm{d}}$ is the distribution factor, $k_{\mathrm{p}}$ is the pitch factor, and $k_{\mathrm{s}}$ is the skew factor.

The winding type is full-pitch lap winding or $k_{\mathrm{p}}=1$. The cross section area of the winding conductor is obtained using Equation (6),

$$
a_{w}=\frac{A_{S S} \cdot F F}{N_{S}}
$$


Where $F F$ is the fill factor defined as 0.3 . Since the system is fully immersed in the water, the current density is set at a quite high value, which is $10 \mathrm{~A} / \mathrm{mm}^{2}$.

The conductor diameter is presented by,

$$
d_{w}=\sqrt{\frac{4 \cdot a_{w}}{\pi}}
$$

The winding parameters, including resistance and inductance, are calculated using Equation (8)-(10).

$$
R_{p h}=\frac{\rho \cdot l}{a_{w}}
$$

With $\rho$ is the electrical resistivity of copper of $1.7 \times 10^{-8} \Omega . \mathrm{m}, l$ is the length of the winding (m), and $a_{\mathrm{w}}$ is in $\mathrm{m}^{2}$. The slot leakage inductance is approached with rectangular shape [19],

$$
L_{s l}=2 \cdot \mu_{0} \cdot N_{p h}^{2} \cdot L_{i} \frac{\lambda_{s}}{p \cdot q}
$$

Where $\mu_{\mathrm{o}}$ is the constant of $4 \cdot \pi \cdot 10^{-7}, L_{\mathrm{i}}$ is the length of the stator core $(\mathrm{m})$, and $\lambda_{\mathrm{s}}$ is the geometrical specific slot permeance (see Figure 3) presented by,

$$
\lambda_{s}=\frac{h_{S}}{3 b_{s}}+\frac{h_{o s}}{b_{o s}}
$$

With $h_{\mathrm{s}}=0.040 \mathrm{~m}, b_{\mathrm{s}}=0.018 \mathrm{~m}, h_{\mathrm{os}}=0.001 \mathrm{~m}, b_{\mathrm{os}}=0.015 \mathrm{~m}$.

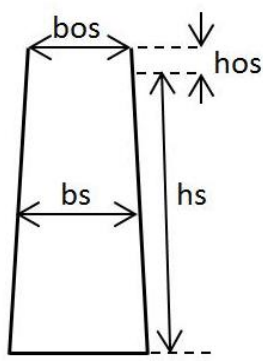

Figure 3. The slot dimensions for the slot leakage inductance calculation

The other leakage inductances consisted of air gap leakage inductance, tooth tip leakage inductance, end winding inductance and skew leakage inductance are calculated referring to [20].

\subsection{Rotor Construction}

Rotor is the rotating part of generator and carries permanent magnets in its body. In most cases, for low speed application, surface mounted magnet or inset magnet configuration is more preferable. In this study, rotor material is mild steel St37, the same as yoke material.The benefit of using permanent magnet is the absence of heat generated in rotor as in wound rotor type. The configuration of the magnets on the rotor body is ilustrated in Figure 4.

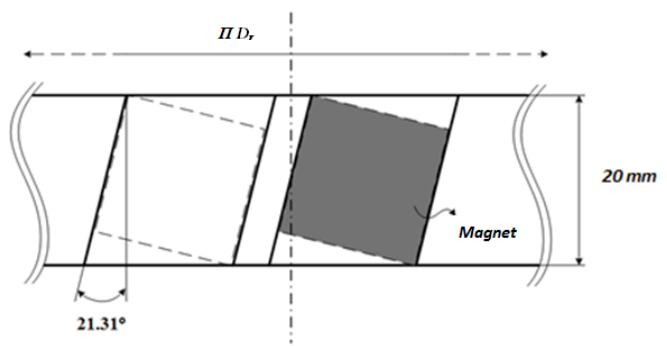

Figure 4. The magnet skewing of the studied generator 
Skewing the magnets is the easiest and the most common method of reducing cogging torque. However, an excessive skewing will lead to a reduced electromotive force. Therefore, there should be a compromised level where the two parameters can be achieved optimally. In Figure 4, the magnet skewing is set at $21.31^{\circ}$.

\subsection{Experimental Set-Up}

The turbine-generator was tested at the laboratory with the experimental set-up as depicted in Figure 5. The measuring devices consist of a variable water resistance serves as the load test, a power quality meter to record current, frequency, voltage, and power. In addition, an induction motor that serves as the prime mover was connected to a speed control. The generator and the induction motor are connected through a three-stage mechanical transmission, pulley belt - gear box - pulley belt. The test was performed at nominal frequency for each type of the stator inner casing material.

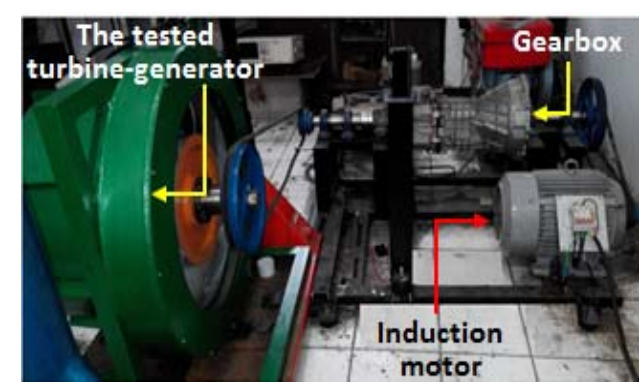

Figure 5. The experiment set-up of generator

\section{RESULTS AND DISCUSSION}

\subsection{The Analitical Calculation Results}

The analytical calculation results of the generator parameters as well as the detailed dimension of the stator and rotor are presented in Table 1 and Figure 6 respectively.

Table 1. Generator parameters

\begin{tabular}{cc}
\hline Parameters & Magnitudes \\
\hline$N_{\mathrm{ph}}$ & 11952 turns \\
$D_{\mathrm{w}}$ & $0.9 \mathrm{~mm}$ \\
$R_{\mathrm{ph}}$ & $29.7 \Omega$ \\
$L_{\mathrm{ph}}$ & $0.197 \mathrm{H}$ \\
\hline
\end{tabular}

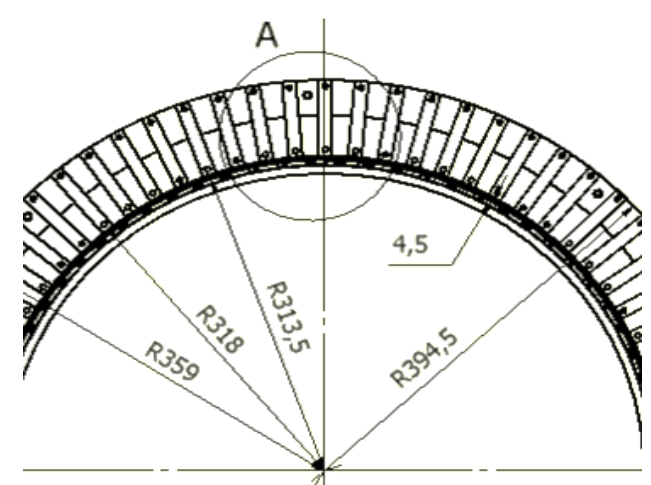

(a)

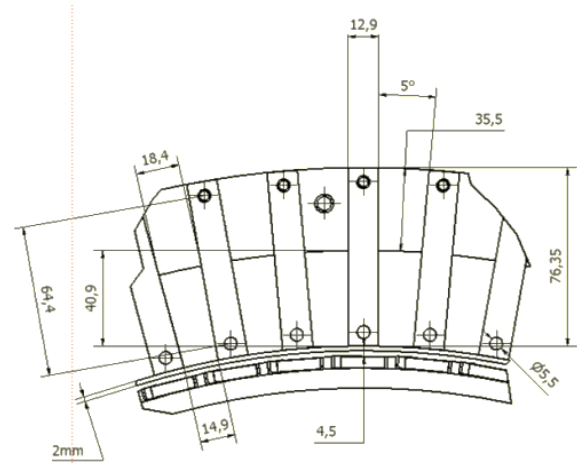

(b)

Figure 6. Detailed dimension of the stator and rotor 
The interaction between winding in the stator slots and permanent magnets in the rotor is exhibited in the form of flux density graphs, taken in two boundary conditions, in the air gap and in the stator slots consecutively. The flux density graphs for both studied casing materials are shown in Figure 7.

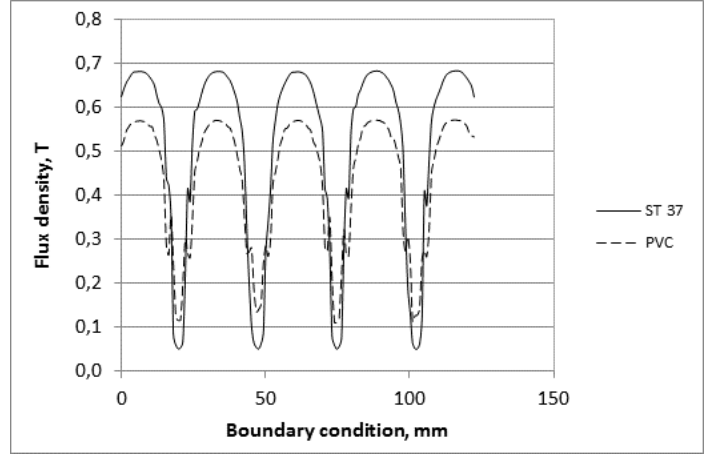

(a)

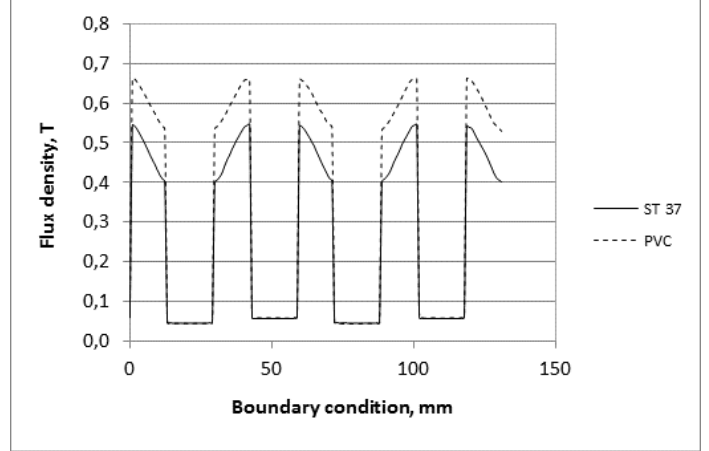

(b)

Figure 7. The flux density characteristic affected by the different types of the stator inner casing materials, (a) In the water gap, (b) In the stator teeth and slots

The graphs illustrate an opposite phenomenom of the flux density due to the different type of the stator inner casing material. In the water gap, higher flux density occurs when the casing of mild steel St37 is applied. In contrast, in the stator teeth and slots, generator with PVC casing generates higher flux density. This is the effect of the value of the relative magnetic permeability, i.e. 100 and 0.75 for mild steel and PVC respectively. In consequence, the mild steel casing absorbs or carries larger magnetic flux, and passes the remaining to the stator teeth and slots whereas the PVC casing forwards almost all of the magnetic flux.

\subsection{The Experiment Results}

The experiment results of the generator performance at nominal frequency are presented in Figure 8.

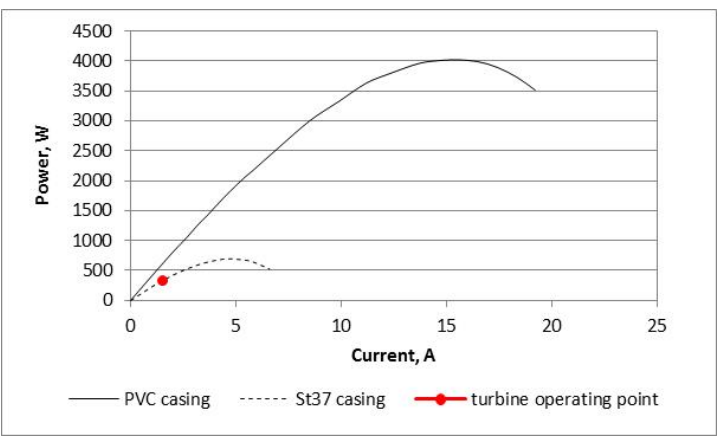

(a)

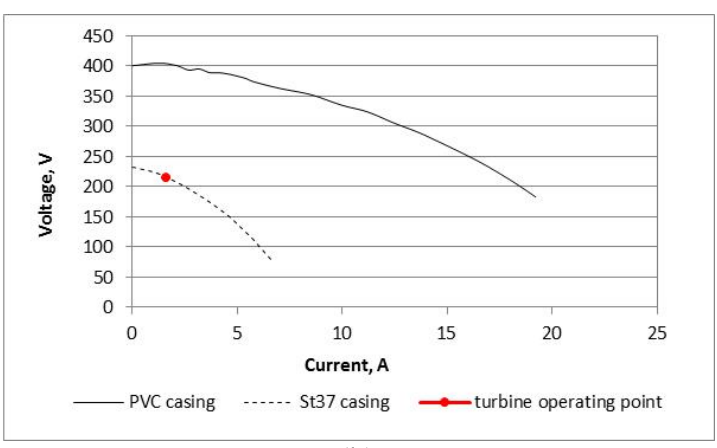

(b)

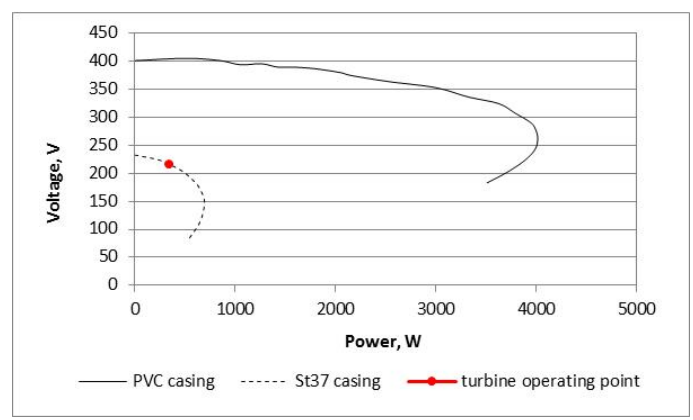

(c)

Figure 8. The experiment results of generator performance, (a) Power vs Current graph, (b) Voltage vs 


\section{Current graph, (c) Voltage vs Power graph}

The figures show that generator with PVC inner casing material possesses higher output power, around 5.8 times, than the one using mild steel St37. Furthermore, Figure 9 compares the waveforms of voltage and current of both material casings and indicates that the sinusoidal waveform using PVC casing is more tapered than that of St37 casing.

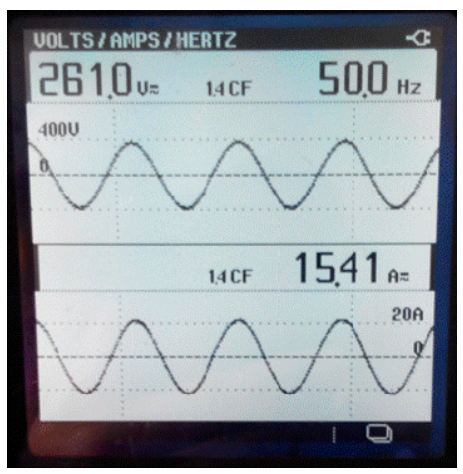

(a)

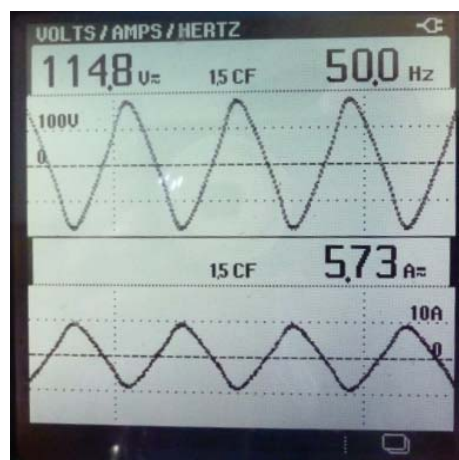

(b)

Figure 9. The current and voltage waveforms of the generator (a) PVC casing, (b) St37 casing

It is already known that waveform is influenced by harmonic content, meaning that low harmonics present in a good waveform quality. In this case, it is shown in Figure 10.

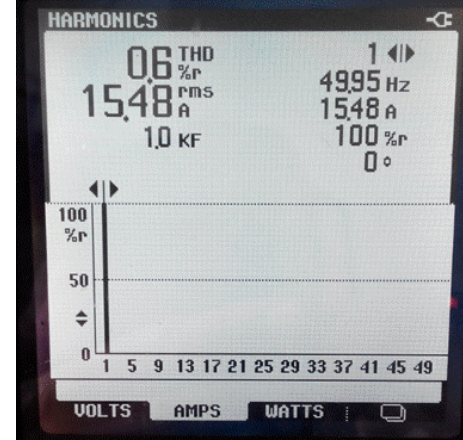

(a)

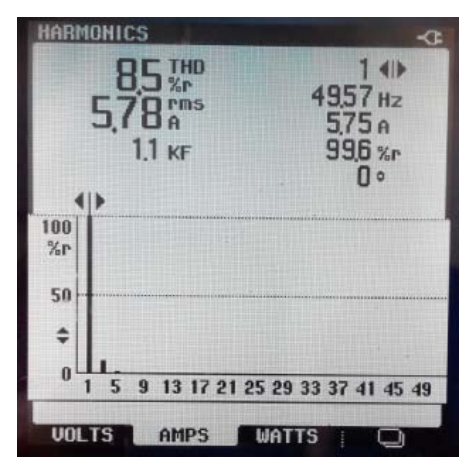

(b)

Figure 10. Total harmonic distortion, (a) PVC casing, (b) St37 casing

At the last stage, the performance of the generator is measured by its efficiency. Based on the experiment procedure, the input power is the power delivered by the induction motor. By taking only the value correlated with the maximum power of the generator, the power of the induction motor are $5761.45 \mathrm{~W}$ (PVC casing) and 5329.52 W (St37 casing). Accordingly, the efficiency of each generator is 69.8\% (PVC casing) and $13.1 \%$ (St37 casing). Those values are relatively low as the power has to pass through a threestep mechanical transmission. If assumed that the losses at the gearbox and the pulley belt is 5\% each [21], [22], by neglecting the transmission system, the generator efficiencies could reach around $84.8 \%$ (PVC casing) and 28.1\% (St37 casing). Compared to the efficiencies of other PMGs with the same topology, 86.2\% - 95.9\% [23]-[25], this study is regarded to have a good preliminary attainment (generator using PVC casing in particular). Nevertheless, if only $300 \mathrm{~W}$ of power ulitized to correspond with the turbine capacity, the generator would be less efficient.

A valuable finding verified by the experiment results is that in the case of a certain material covers stator surface, the design calculation should not refer to the air or water gap flux density but on the flux density in the stator slots and teeth instead. 


\subsection{The Temperature Distribution}

Another parameter observed is the heat distribution as depicted in Figure 11.

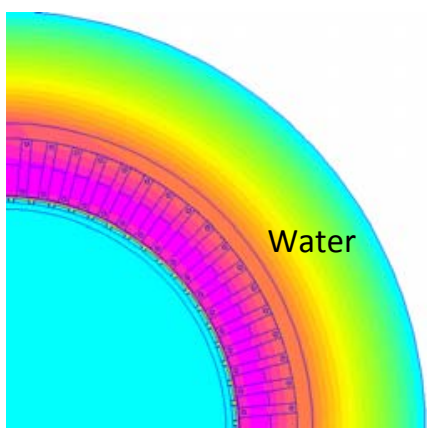

(a)

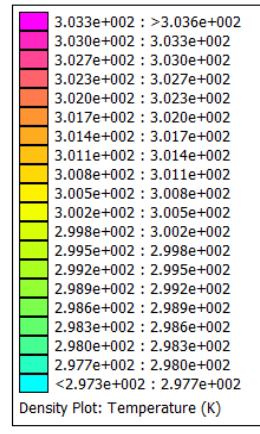
Density Plot: Temperature $(K)$
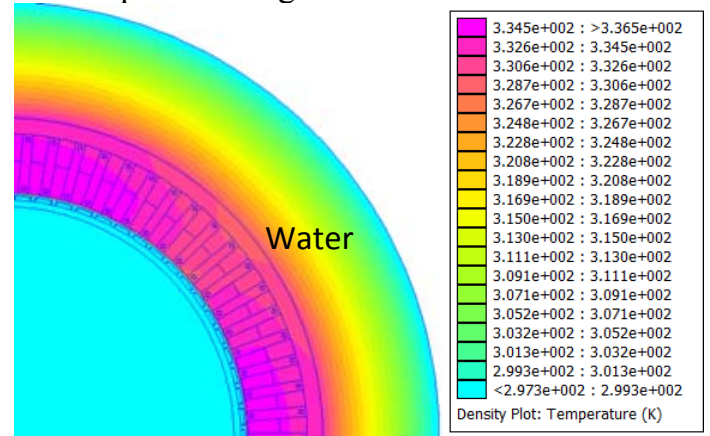

(b)

Figure 11. The simulation results of heat distribution, (a) St37 casing, (b) PVC casing

In the simulation, water is the outer boundary condition to create a realistic environment. Having better heat conductivity, St37 casing can easily dissipate the heat to its surrounding. However, using PVC casing, higher heat is held up in the winding, although still in a safe level for PVC material because it is under $80^{\circ} \mathrm{C}$ or $353 \mathrm{~K}$.

\section{CONCLUSION}

The performance measurement of a compact generator - hydro turbine system has been discussed in this paper. The system is built by employing the construction of integrated stator with individual teeth and yoke as well as utilizing turbine's blade circumference as the rotor of the generator. The influences of the type of the stator inner casing material, PVC and mild steel St37, to the generator performance have also been investigated. A noteworthy result is the opposite values of flux density in the air gap and in the slots, where the lattest affecting the output power. As demonstrated by the experiment results, generator using PVC casing gives much better performance in many aspects, including the power, the waveform, and the harmonic content.

Due to conforming to the turbine capacity, the generator becomes underused since only $300 \mathrm{~W}$ of power should be generated out of $4000 \mathrm{~W}$. Future work is still needed to match the turbine capacity, by using an open flume turbine with the head more than 2 meters. Hence, the power equality between the turbine and the generator can be achieved.

\section{ACKNOWLEDGEMENTS}

This work was supported by Research Fund from Decentralization DIKTI LPPM ITB 2015 (Bandung Institute of Technology) and Indonesian Institute of Sciences (LIPI).

\section{REFERENCES}

[1] S. P. Adhau, R. M. Moharil, and P. G. Adhau. "Mini-hydro power generation on existing irrigation projects: Case study of Indian sites," Renewable and Sustainable Energy Reviews, Vol. 16, No. 7, pp. 4785-4795, 2012.

[2] C. h. Corp. "Very Low Head (VLH) Turbine," 11 $1^{\text {th }}$ Annual Power of Water Conference, Ontario, 2011.

[3] S. J. Williamson, B. H. Stark, and J. D. Booker. "Performance of a low-head pico-hydro Turgo turbine," Applied Energy, Vol. 102, pp. 1114-1126, 2013.

[4] A. Muis, and P. Sutikno. "Design and Simulation of Very Low Head Axial Hydraulic Turbine with Variation of Swirl Velocity Criterion," International Journal of Fluid Machinery and System,Vol. 7, No. 2, pp. 68-79, 2014.

[5] A. Date, and A. Akbarzadeh. "Investigating the Potential for Using a Simple Water Reaction Turbine for Power Production from Low Head Hydro Resources," Energy Conversion and Management, Vol. 66, pp. 257-270, 2013.

[6] J. Senior, P. Wiemann, G. Müller. "The Rotary Hydraulic Pressure Machine for Very Low Head Hydropower Sites," Proc. Hidroenergia, Session 5B(1), Slovenia, European, 2008.

[7] D. Abhijit, D. Ashwin, A. Akbarzadeh, and F. Alam. "Examining the Potential of Split Reaction Water Turbine for Ultra-Low Head Hydro Resources," Evolving Energy-IEF International Energy Congress (IEF-IEC 2012), Sydney, Australia, pp. $197-204,2012$.

[8] K. V. Alexander, and E. P. Giddens. "Microhydro: Cost-effective, Modular Systems for Low Heads," Renewable Energy, Vol. 33, No. 6, pp. 1379-1391, 2008. 
[9] S. J. Williamson, B. H. Stark, and J. D. Booker. "Performance of a Low-Head Pico-Hydro Turgo Turbine," Applied Energy, Vol. 102, pp. 1114-1126, 2013.

[10] K. Trinadha, A. Kumar, and K. S. Sandhu. "Study of Wind Turbine based SEIG under Balanced/Unbalanced Loads and Excitation," International Journal of Electrical and Computer Engineering (IJECE), Vol. 3, No. 2, pp. 353-370, 2012.

[11] M. Anju, and R. Rajasekaran. "Power System Stability Enhancement and Improvement of LVRT Capability of a DFIG Based Wind Power System by Using SMES and SFCL," International Journal of Electrical and Computer Engineering (IJECE), Vol. 3, No. 5. pp. 618-628, 2013.

[12] E. Kurt, H. Gör, and M. Demirtas. "Theoretical and Experimental Analyses of a Single Phase Permanent Magnet Generator (PMG) with Multiple Cores Having Axial and Radial Directed Fluxes," Energy Conversion and Management, Vol. 77, pp. 163-172, 2014.

[13] G. C. Lee, S. M. Kang, and T. U. Jung. "Permanent Magnet Structure Design of Outer Rotor Radial Flux Permanent Magnet Generator for Reduction Cogging Torque with Design of Experiment," International Conference on Electrical Machines and Systems, Busan, Korea, pp. 315-319, 2013.

[14] P. Wannakarn, T. Tanmaneeprasert, N. Rugthaicharoencheep, and S. Nedphograw. "Design and Construction of Axial Flux Permanent Magnet Generator for Wind Turbine Generated DC Voltage at Rated Power 1500 W," International Conference on Electric Utility Deregulation and Restructuring and Power Technologies (DRPT), pp. 763-766, 2011.

[15] S. M. Mohiuddin, and M. R. I. Sheikh, "Stabilization of Solar-Wind Hybrid Power System by Using SMES," International Journal of Electrical and Computer Engineering (IJECE), Vol. 4, No. 3, pp. 351-358, 2014.

[16] A. R. Bahman, E. Alialhosseini, "Change in hardness, yield strength and UTS of welded joints produced in St37 grade steel," Indian Journal of Science and Technology, Vol. 3, No. 12, pp. 1162-1164, 2010.

[17] R. A. Rahbar, and A. H. Zakeri. "Mechanical Properties and Corrosion Resistance of Normal Strength and High Strength Steels in Chloride Solution," Journal of Naval Architecture and Marine Engineering, Vol. 3, pp. 93-100, 2010.

[18] R. L. Lehman, and M. G. McLaren, "Mechanical Engineering Handbook," In Material. F. Kreith, Ed. ed Boca Raton: CRC Press LLC, 1999.

[19] I. Boldea, and S. A. Nasar. "The Induction Machine Handbook," Florida, CRC Press, 2000.

[20] P. Salminen. "Fractional Slot Permanent Magnet Synchronous Motors For Low Speed Applications," Lappeenranta University of Technology Lappeenranta, Finland, PhD Thesis, 2014.

[21] C. Schlegel, A. Hosl, and S. Diel. "Detailed Loss Modelling of Vehicle Gearboxes," $7^{\text {th }}$ Modelica Conference, Como, Italy, pp. 434-113, 2009.

[22] L. C. Company. "Engineering Cookbook: A Handbook for the Mechanical Designer," Second Edition ed. Springfield, MO, 1999.

[23] S. Eriksson, A. Solum, M. Leijon, and H. Bernhoff, "Simulations and Experiments on a $12 \mathrm{~kW}$ Direct Driven PM Synchronous Generator for Wind Power," Renewable Energy, Vol. 33, pp. 674-681, 2008.

[24] J. Y. Choi, S. M. Jang, and B. M. Song, "Design of a Direct-Coupled Radial-Flux Permanent Magnet Generator for Wind Turbines," Power and Energy Society General Meeting, 2010 IEEE. Minneapolis, MN, pp. 1-6, 2010.

[25] T. F. Chan, L. L. Lai, and L. T. Yan, "Performance of a Three-Phase AC Generator With Inset NdFeB PermanentMagnet Rotor," IEEE Transaction on Energy Conversion, Vol. 1, No. 19, pp. 88-94, 2004.

\section{BIOGRAPHIES OF AUTHORS}

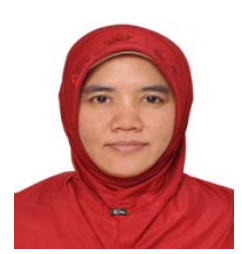

Pudji Irasari received electrical engineering degree in 1994 from Brawijaya University and master degree in renewable energy in 2003 from Oldenburg university. Currently she is a senior researcher under research group of power electronics and electric machines at Research Centre for Electrical Power and Mechatronics, Indonesian Institute of Sciences.

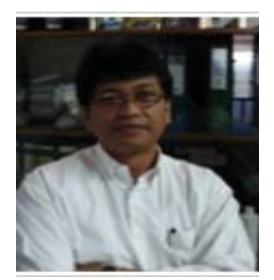

Priyono Sutikno completed his bachelor degree in Mechanical Engineering, Bandung Institute of Technology (ITB), in 1976. He continued his master study in Automatic Control ENSM in 1981 and received his Diplome de Docteur Enginieur in 1984 from the University of de Perpignan, France. His research interest and competence include Fluid Mechanic, Turbomachinery, CFD. Currently he is an Associate Professor at the Laboratoryof Fluid Machinery and Fluid Mechanics, ITB. 


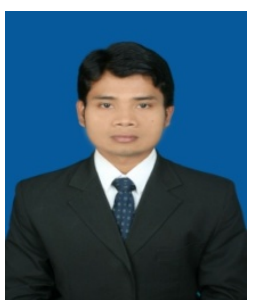

Puji Widiyanto finished his bachelor degree in technical engineering, Mandala College of Technolgy, in 2011. He is currently a master student of Power Generation System at Fluid Machinery and Fluid Mechanics Lab. ITB and a researcher at Research Centre for Electrical Power and Mechatronic, Indonesian Institute of Sciences.

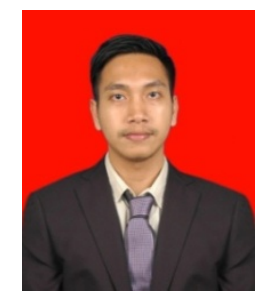

Qidun Maulana received his bachelor degree in Physics of Engineering, Gadjah Mada University in 2010, and finished his master degree in Mechanical Engineering, Gadjah Mada University in 2013. Currently he is a junior researcher at Research Centre for Electrical Power and Mechatronic, Indonesian Institute of Sciences. His current research is to investigate the flow characteristic of propeller hydro turbine using computational fluid dynamics. 